\title{
Study On Decision-Making For Café Management Alternatives
}

\author{
Cheng-I Hou \\ Yu Da University of Science and Technology, Taiwan \\ Chung Hua University, Taiwan
}

\begin{abstract}
In recent years, many new cafés have emerged onto the market. Other than view cafés, beautiful cafés that seem as if they came from Paris or New York have gradually appeared in leisure and quiet residential areas, in alleyways, in peripheral areas, and in local commercial areas. In particular, leisure is trendy at present, and modern restaurants innovate in terms of their food, leisure, and consumption. Unlike traditional restaurants, they are able to develop into cafés with unique styles to attract consumers. Even though not all of these new cafés are successful, as cafés are an industry that is at the forefront of fashion, many individuals who dream of entrepreneurship would want to open a café. However, as there are many types of cafés on the market, what type and style of cafés are the most suitable? An overview of cafés in Taiwan shows that each café offer unique services and functions to attract consumers, which is the key to sustainable operations of cafés. Therefore, this study explores the decisions of companies when choosing the style for their cafés. This study uses the analytical hierarchy process $(A H P)$ to explore the selection of café styles, in order to provide references for café operators to achieve successful and sustainable operations. Based on literature review, expert interviews, and AHP, this study intends to provide useful results to the operators of cafés.
\end{abstract}

\section{KEYWORDS}

Decision Making, View Cafés, Analytical Hierarchy Process

\section{INTRODUCTION}

Since the government began implementing two-day weekends to stimulate the tourism market in Taiwan, going outside into nature has become an important part of tourism in Taiwan. Unique natural landscapes, mountains and rivers, forest and streams, and various plants and flowers in connection to culture and art in cafés, as well as the landscape, are all popular destinations for the public on weekends. The first priority in determining the type of style in a café is to conduct an objective self-evaluation. Choosing the right style for the store is the key factor in the success or failure of the café. Cafés not only need to provide delicious food and attractive interior décor; a successful café requires complete devotion and attention to details.

An overview of cafés in Taiwan shows that there is a common feature, namely, that it can fully demonstrate the operator's style. Regardless of whether it is the design, music, or taste preferred by the operator, they would be completely released in this space, thus, it can resonate with consumers, who in turn gather in the spaces. Most cafés have unique styles and amicable interaction with consumers, thus attracting returning consumers. Besides the gourmet foods that impress consumers, the styles of cafés are also reasons for consumer revisits. Regardless of where cafés open, provided it has a strong personal style, consumers who like the same style would naturally visit. 
The styles of cafés include décor, which refers to the sensory effects of the café, as well as the unique sense of design by the operator; these are tools to attract consumers. Styles of cafés on the market can be divided into the three types, namely, fashion cafés, theme cafés, and view cafés. Fashion cafés generally understand cultural trends and demonstrate sensitive and avant-garde styles. Theme cafés are usually based on the personal preferences of the operators, establishing various types of theme cafés, based on music, books, antiques, or maids.

View cafés not only provide food services, such as coffee and snacks, but also utilize natural or artificial scenery. Every view café has its unique style or atmosphere. Besides natural scenery, owners would decorate their cafés in accordance with nearby scenery. By combining coffee and scenery, customers with different needs are attracted to such cafés. On the whole, as view cafés provide consumers with services aside from coffee by incorporating beautiful visual sceneries, they can offer higher-quality leisure experiences in terms of consumer vision and environment.

There are many essential elements to opening cafés, including capital, the number of employees, and the size of the store. The success or failure of cafés is also related to the style of cafés. This study uses the analytic hierarchy process (AHP) to explore the factors considered by operators in choosing a style of café, in turn elevating the probability of success, and achieving the objective of sustainable operations.

\section{LITERATURE REVIEW}

In order to collect data on current elements and styles of cafés, this study uses the following research methods and steps listed:

\subsection{Analytic Hierarchy Process (AHP)}

AHP was first proposed by American scholar Saaty. in late 1970s [1]. It is a method that combines qualitative and quantitative features, which can be used to process complex social, political, economic, and technical problems for decision-making. It can systematize, modularize, and digitize complex decision-making thinking and processes, and can solve multi-objective, multi-level, and multi-criteria problems. In particular, it offers considerable precision in ascertaining the weight factors of various evaluation indicators. The procedure of AHP is to divide complex questions into various component factors, and use relationships to categorize these elements. They thus form orderly hierarchical structures on the basis of which paired comparisons are used to determine the relative importance of the elements in the levels. Finally, these determinations are used to obtain the weights of elements in the decision-making process, thus, decision-makers can identify the relationships among influential factors.

Teng and Tseng [2,3] suggested that the usage of AHP can be divided into two parts: establish the hierarchy, and evaluate the hierarchy. In the AHP, complex problems are evaluated by experts and scholars on the initial elements, and then expressed in simple hierarchical structures. After determining the eigenvectors, the priorities of elements in the hierarchy are compared. The consistency of paired matrices is evaluated to find out whether there are any errors, and whether it can be used as a reference. Figure 1 shows the process of AHP. 


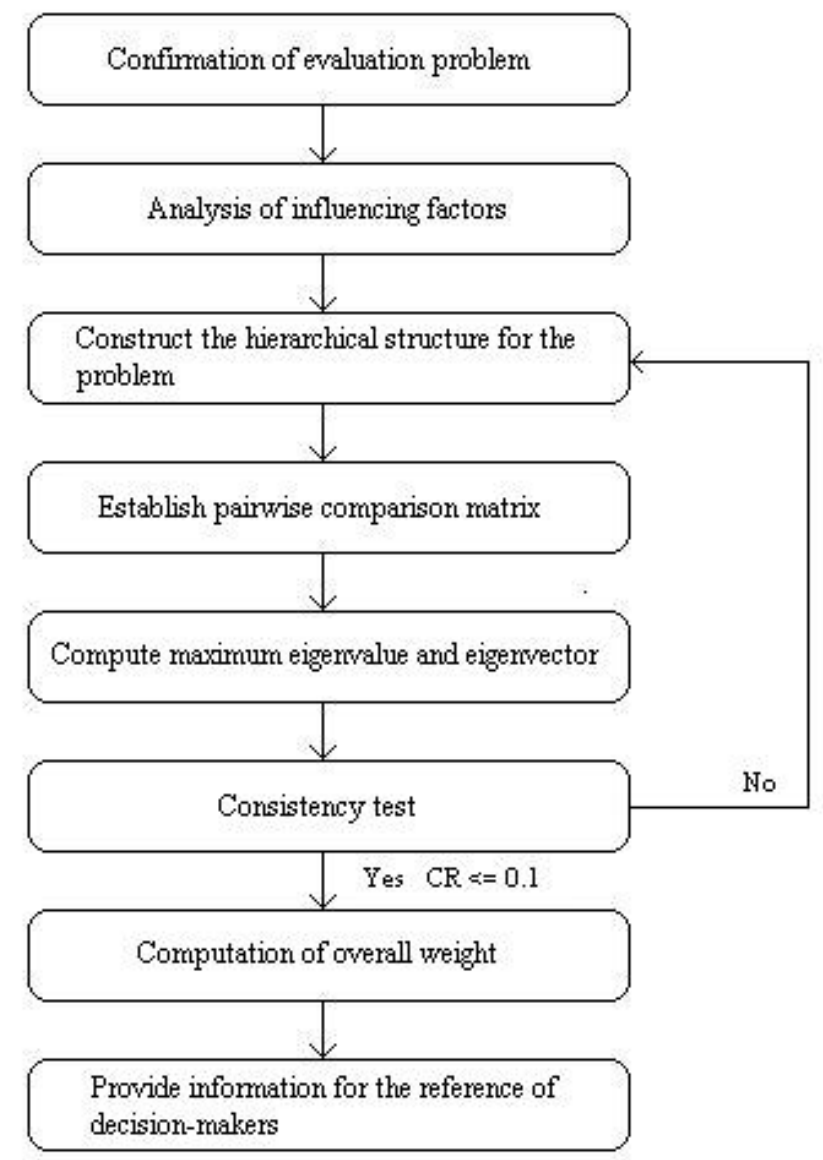

Figure 1. AHP process [2, 3]

AHP uses the hierarchical structure to create systematic connections among complex relationships that exist among factors. As it performs paired factor comparison, the thoughts and intentions of experts can be clearly and effectively expressed.

AHP first analyzes and categorizes complex decision-making problems into related hierarchical structures, where each element in a level is developed in a tree-style based on connections. Then, experts are invited to compare pairs of elements in the same level to determine the relative importance. Then, linear algebraic methods are used to solve the relative importance of decision factors in each level compared to the objectives in the higher level and the topmost level (which can be seen as levels of priority). This method is used to compute downward for the relative importance (priorities). Finally, the elemental weights that affect an objective in a decisionmaking system are computed.

AHP is theoretically simple and easy to operate, and it is possible to effectively arrive at a common consensus among most experts and decision-makers. Complex influential and evaluation factors can be expressed in a simple hierarchical structure, as shown in Figure 2, rendering it easier for decision-makers to accept the relationships among factors [4-11]. 


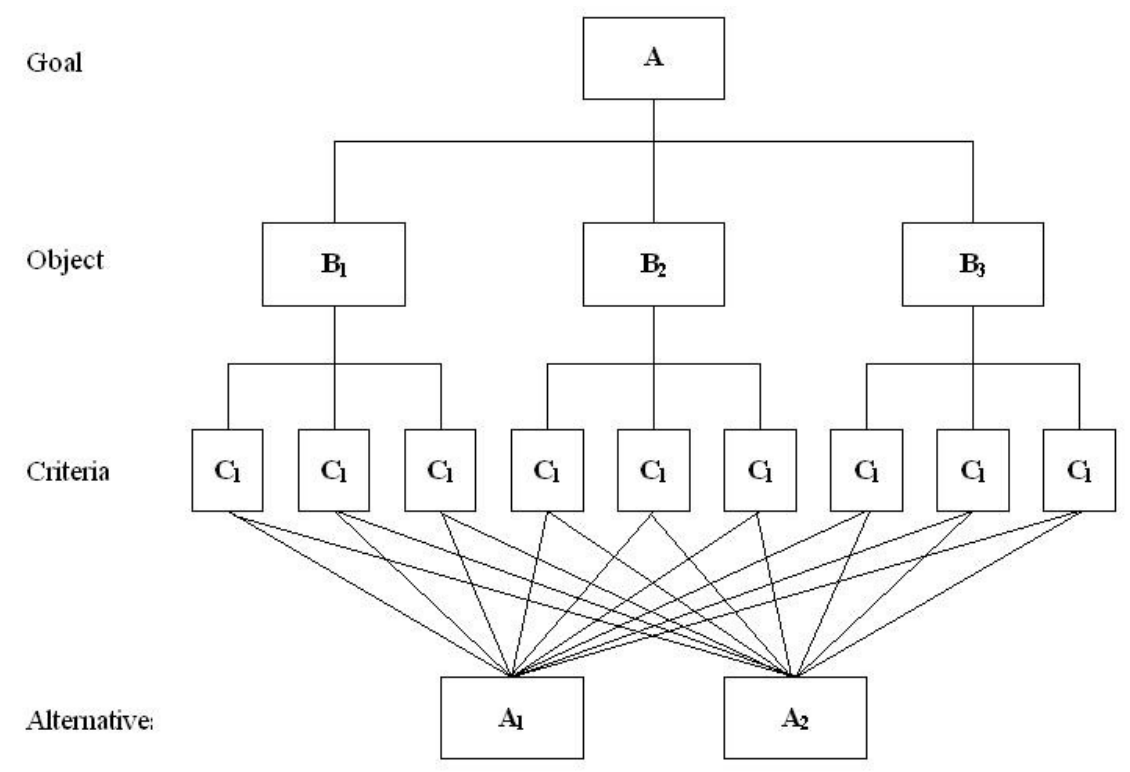

Figure 2. AHP hierarchical structure [2,3]

\subsection{Interview Survey Method}

Besides literature review, this study carried out discussions with personnel in the coffee industry, food industry, hotel industry, and leisure and recreation industries. The purpose was to understand their preferences for the styles of cafés, as well as their personal experiences, in order to gain more specific data. The data collected from the interviews were used to design the questionnaire. The results of interviews were used to evaluate factors with important influence, and the questionnaire system was used to collect research and analytical samples for further understanding. Evaluation of the designed questionnaire and subsequent analysis are the main procedures involved in this study. It is intended that this method can allow greater understanding of the selection of styles of cafés [4-11].

Elements in each level have elements in the level above as the evaluation criteria for paired comparison. Therefore, each paired comparison is based on a 1-9 scale. The subjects responded by ticking the corresponding scale for each paired element comparison. Based on the results of questionnaire surveys, the paired comparison matrices were established. A computer was used to extract the eigen values and eigenvectors of each comparison matrix, and establish the consistency of matrices. [4-11]

\section{Research Method and Procedures}

The research procedures are shown in Figure 3, including literature analysis, professional interviews, and questionnaire surveys. The important factors in views regarding the selection of café styles were investigated. The research framework of this study included questionnaire collection and analysis, questionnaire evaluations, and subsequent analysis. Finally, AHP was used to analyze samples and order, as well as summarize the factors in choosing café styles and the weighted relationships. AHP separates the levels into systematized complex problems, and uses quantitative scoring to determine and analyze the weighted values of elements by levels, which serve as the foundation for overall reference. 


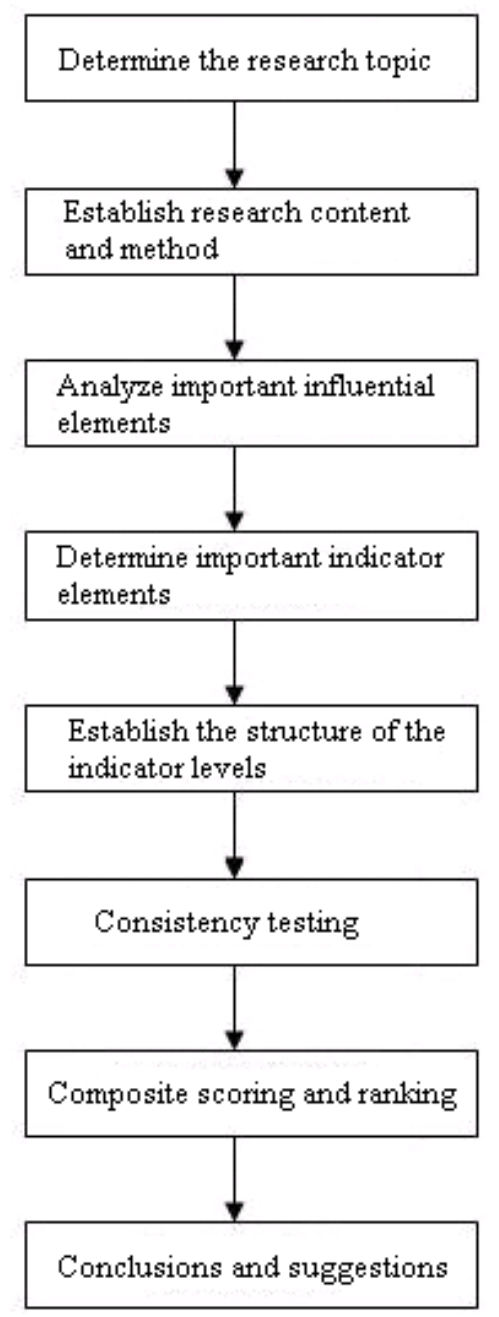

Figure 3. Research flowchart [7-11]

Cafés in Taiwan have their unique styles to attract the attention of consumers, but what standards were used in choosing the styles? Thus, this study seeks to explore this dimension, and attempts to discover the priorities and criteria for operators of cafés when choosing a style. The findings can provide future café operators with a reference for modification or enhancement of their operations. AHP was used to construct the "Scale for café style selection evaluation," as shown in Figure 4. A questionnaire was designed for survey. The collected data were analyzed to conduct critical analysis on choosing café styles. 


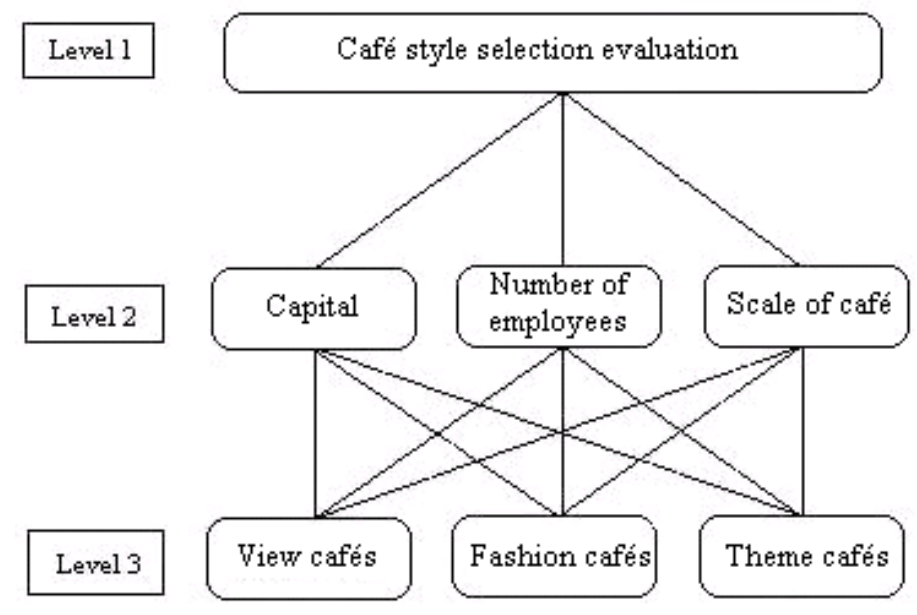

Figure 4. Café style selection evaluation level frameworks

The exploration of choices for café styles are divided into three levels: 1) café style selection evaluation; 2) the evaluation factors level; 3) the lowest alternatives level. The factors are compared in pairs and divided into five scales (see the explanation in Table 1), with equally strong, slightly strong, quite strong, extremely strong, absolutely strong, and a median value. The questionnaire method is used to form the framework for paired comparison matrices, in which group decision-making is used to integrate the analysis and compute the factor evaluation values of each level.

Table 1. AHP evaluation scale semantics and descriptions [4-11]

\begin{tabular}{|l|l|l|}
\hline Scale evaluation & Semantics & Meaning descriptions \\
\hline 1 & $\begin{array}{l}\text { Equally strong } \\
\text { (equally important) }\end{array}$ & Two factors are equally important \\
\hline 3 & $\begin{array}{l}\text { Slightly stronger } \\
\text { (slightly more important) }\end{array}$ & $\begin{array}{l}\text { According to experience/judgment, one } \\
\text { factor is slightly more important than } \\
\text { another }\end{array}$ \\
\hline 5 & $\begin{array}{l}\text { Quite strong } \\
\text { (quite important) }\end{array}$ & $\begin{array}{l}\text { According to experience/judgment, a factor } \\
\text { is strongly preferred. }\end{array}$ \\
\hline 7 & $\begin{array}{l}\text { Extremely strong } \\
\text { (extremely strong) }\end{array}$ & A factor is extremely preferred. \\
\hline 9 & $\begin{array}{l}\text { Absolutely strong } \\
\text { (absolutely important) }\end{array}$ & $\begin{array}{l}\text { A factor is evidenced as absolutely } \\
\text { important. }\end{array}$ \\
\hline $2,4,6,8$ & $\begin{array}{l}\text { Two adjacent } \\
\text { intermediate values }\end{array}$ & $\begin{array}{l}\text { A compromise value between the above } \\
\text { descriptions }\end{array}$ \\
\hline
\end{tabular}

\section{RESEARCH RESULTS}

Excel and Expert Choice 2000 were used to analyze the data, and the weight analysis and verification process for the measurement dimensions using AHP method are:

The paired comparison matrices obtained using Expert Choice for analysis of the data is as shown in Table 2: 
International Journal of Computer Science \& Information Technology (IJCSIT) Vol 5, No 6, December 2013

Table 2. Paired comparison matrices of influential factors in the second level

\begin{tabular}{|l|l|l|l|}
\hline Influence factors & Capital & Number of employees & Scale of café \\
\hline Capital & 1 & 7.4 & 8.3 \\
\hline Number of employees & 0.135135135 & 1 & 2.6 \\
\hline Scale of café & 0.120481928 & 0.384615385 & 1 \\
\hline Column total & 1.255617063 & 8.784615385 & 11.9 \\
\hline
\end{tabular}

Using the column sums of the influential factors of the rows in Table 2, standardized value computations are conducted, as shown in Table 3:

Table 3. Standardized paired comparison matrices and weight values of influential factors in the second level

\begin{tabular}{|l|l|l|l|l|}
\hline Influence factors & Capital & $\begin{array}{l}\text { Number of } \\
\text { employees }\end{array}$ & Scale of café & Weight \\
\hline Capital & 1 & 7.4 & 8.3 & 0.778761 \\
\hline Number of employees & 0.135135135 & 1 & 2.6 & 0.146649 \\
\hline Scale of café & 0.120481928 & 0.384615385 & 1 & 0.07459 \\
\hline
\end{tabular}

This conforms to the AHP requirements proposed by Saaty; C.I. $<=0.1 \&$ C.R. $<=0.1$; therefore, the consistency of this matrix is satisfactory. The remaining target dimensions and indicators are also confirmed through this process, and the summary analysis shows that C.I. $<=0.1$ and C.R. $<=0.1$. Hence, the consistency of this matrix is satisfactory, as shown in Table 4.

Table 4. Weight values and consistency values

\begin{tabular}{|l|l|l|l|l|}
\hline Target dimension & $\begin{array}{l}\text { Evaluation } \\
\text { criteria }\end{array}$ & Weight values & Ranking & Consistency value \\
\hline $\begin{array}{l}\text { Café style } \\
\text { selection } \\
\text { evaluation }\end{array}$ & Capital & 0.778761 & 1 & $\begin{array}{l}\text { C.I. }=0.040434851 \\
\text { C.R. }=0.06971526 \\
\text { C.I. }<=0.1 \\
\&\end{array}$ \\
\cline { 2 - 4 } & $\begin{array}{l}\text { Number of } \\
\text { Cemployees }\end{array}$ & 0.146649 & 2 & 0.1 \\
\cline { 2 - 4 } & Scale of café & 0.07459 & 3 & \\
\hline
\end{tabular}

According to this computation method, the weight values and consistency values in Table 5 are derived:

Table 5. Weight values and consistency values

\begin{tabular}{|l|l|l|l|l|}
\hline Factor dimension & Evaluation criteria & Weight values & Ranking & $\begin{array}{l}\text { Consistency } \\
\text { values }\end{array}$ \\
\hline \multirow{4}{*}{ Capital } & View cafés & 0.357584 & 2 & C.I. $=0.03868$ \\
& Fashion cafés & 0.516845 & 1 & C.R. $=0.06669$ \\
\cline { 2 - 4 } & Theme cafés & 0.125571 & 3 & \\
\hline \multirow{2}{*}{$\begin{array}{l}\text { Number of } \\
\text { employees }\end{array}$} & View cafés & 0.456149 & 1 & C.I. $=0.05530$ \\
\cline { 2 - 4 } & Fashion cafés & 0.451729 & 2 & \multirow{2}{*}{ C.R. $=0.09534$} \\
\cline { 2 - 4 } & Theme cafés & 0.092122 & 3 & \\
\hline \multirow{3}{*}{ Scale of café } & View cafés & 0.58688 & 1 & \multirow{2}{*}{ C.I. $=0.05528$} \\
\cline { 2 - 4 } & Fashion cafés & 0.347708 & 2 & C.R. $=0.09531$ \\
\cline { 2 - 4 } & Theme cafés & 0.065412 & 3 & \\
\hline
\end{tabular}


The results of consistency testing are shown in Table 6. It is observed that the first café style selection is "fashion cafés," followed by "view cafés," and the third is "theme cafés," as shown in Figure 5.

Table 6. Overall weighted evaluation chart

\begin{tabular}{|l|l|l|}
\hline Chosen alternative & Overall weighted evaluation & Ranking \\
\hline View cafés & 0.389142145 & 2 \\
\hline Fashion cafés & 0.494679594 & 1 \\
\hline Theme cafés & 0.116178261 & 3 \\
\hline
\end{tabular}

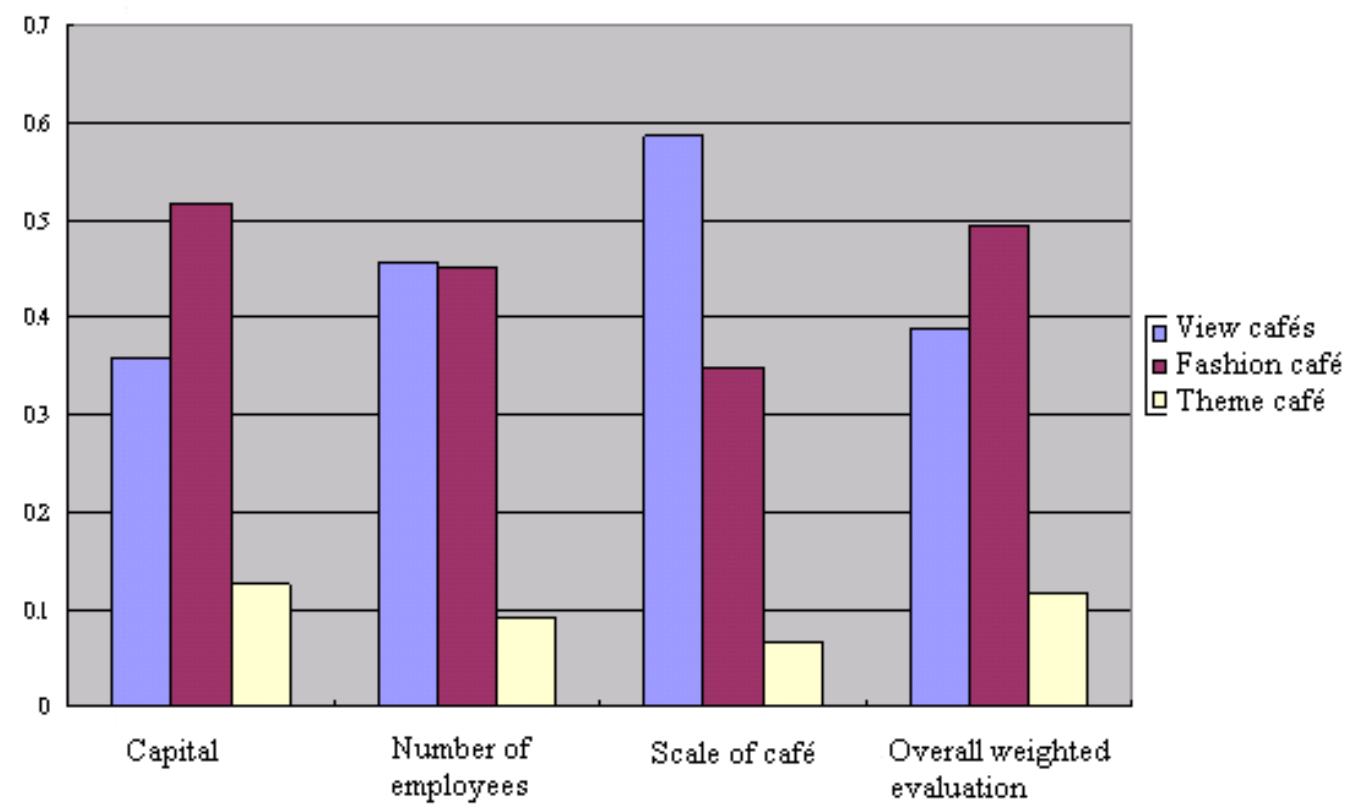

Figure 5. Overall weighted evaluation diagram

As shown above, in terms of café style selection evaluations, operators are most concerned with "fashion cafés," followed by "view cafés," and finally by "theme cafés."

\section{Conclusions}

The operation of a successful café requires unique personal style to attract consumers. The selection of café styles has become increasingly diversified, and analysis based only on traditional impressions and maximum profit is no longer sufficient for the correct choice of a suitable style. When there is insufficient or incomplete data, the basis for determinations change. This study found that current selection evaluations of café styles are focused on fashion cafés and view cafés, and while the ratio of theme cafés is small. The difference in the ratio of fashion cafés and view cafés is not large. Perhaps in urban areas fashion cafés are more popular, while view cafés are more popular in the suburbs, as most view cafés are located in scenic areas. The selection of location is discussed in another article [9]. 
International Journal of Computer Science \& Information Technology (IJCSIT) Vol 5, No 6, December 2013

\section{REFERENCES}

[1] Saaty, T.L. (1980) The Analytic Hierarchy Process, McGraw-Hill, New York.

[2] Teng, J.Y. \& Tzeng, G.H., (1989) "The Analytic Hierarchy Process: Concepts, Techniques and Applications (I)", Journal of the Chinese Statistical Association, Vol. 27, No. 6, pp. 5-22.

[3] Teng, J.Y. \& Tzeng, G.H., (1989) "The Analytic Hierarchy Process: Concepts, Techniques and Applications (II)", Journal of the Chinese Statistical Association, Vol. 27, No. 7, pp. 1-20.

[4] Li, T.S. \& Huang, B.Y., (2008) "The Study of Applying Fuzzy Analytic Hierarchy Process in Supplier Selection”, Journal of Quantitative Management, Vol. 5, No. 2, pp. 39-56.

[5] Chan, T.S. \& Kumar, N., (2007) "Global supplier development considering risk factors using fuzzy extended AHP-based approach”, Omega, Vol. 35, No. 4, pp.417-431.

[6] Lo, C.Y., Hsu, H.C., Hou, C.I. \& Liao, Y.S., (2008) "AHP application of the decision-making choice of hotels", The 2008 Information Management International Conference of Yu-Da College of Business, Miaoli, Taiwan, June, pp. 381-393.

[7] Hou, C.I., Lo, C.Y. \& Huang, H.C., (2013) "The Views of Workers in the Leisure Industry on Karma," International Journal of Leisure Information Management, Vol. 1, No. 2, pp. 5-11.

[8] Hou, C.I., Chang, H.I., Ku, C.T. \& Kulikowski, L., (2013) "Using AHP to Compare and Select Leisure Agricultural Area Land Investment Alternatives," International Journal of Leisure Information Management, Vol. 1, No. 1, pp. 1-6.

[9] Hou, C.I., Huang, H.C., Lo, C.Y. \& Tsai, Y.H., (2014) "A Study of Using AHP to Discuss Landscape Cafe Site Selection”, Advanced Management Journal, Vol. 1, No. 1, pp. 1-7.

[10] Hou, C.I., Huang, H.C. \& Lo, C.Y., (2014) "Study on Decision Making to Construct Coffee Shop Ecommerce Websites", International Journal of Leisure Business Management, Vol.2, No. 1, pp. 12-19.

[11] Hou, C.I., Huang, H.C. \& Lo, C.Y., (2014) “A Study on Coffee Product Categories Sold in Landscape Coffee Shops”, Research Journal of Applied Sciences and Technology, Vol. 1, No. 1, pp. 1-8.

\section{Authors}

Hou, Cheng-I received the Ph.D. degree in Information Systems from Nova Southeastern University, Florida U.S.A. in 1991, as an Associate Professor. His research interests are using Information Technology to solve Leisure Management problems.

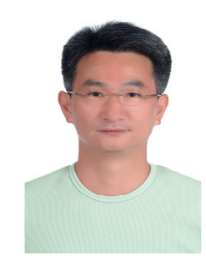

